This is the authors' pre-print manuscript as submitted for refereeing and publication. The penultimate, refereed, publisher-formatted PDF may be available through the journal web site or, your college and university library.

\title{
A "knowledge profile" of an engineering occupation: temporal patterns in the use of engineering knowledge
}

Julie Gainsburg; Carlos Rodriguez-Lluesma; Diane E. Bailey

\section{Manuscript Citation}

The following (APA) citation may be used to reference this manuscript:

Gainsburg, J., Rodriguez-Lluesma, C., Bailey, D. (2010). A "knowledge profile" of an engineering occupation: temporal patterns in the use of engineering knowledge.

Retrieved from http://scholarworks.csun.edu

\section{Published Version Information}

Citation: Gainsburg, J., Rodriguez-Lluesma, C., Bailey, D. (2010). A "knowledge profile" of an engineering occupation: temporal patterns in the use of engineering knowledge.Engineering Studies, 2:3, 197-219. First published on: 13 October 2010

DOI:10.1080/19378629.2010.519773

Copyright: Copyright $\odot$ Taylor \& Francis Group, LLC

Digital Object Identifier (DOI): 10.1080/19378629.2010.519773

This item was retrieved from CSUN ScholarWorks, the open-access, institutional repository of California State University, Northridge. http://scholarworks.csun.edu 


\title{
A "KNOWLEDGE PROFILE" OF AN ENGINEERING OCCUPATION: \\ TEMPORAL PATTERNS IN THE USE OF ENGINEERING KNOWLEDGE
}

\author{
JULIE GAINSBURG \\ Michael D. Eisner College of Education \\ California State University, Northridge \\ CARLOS RODRIGUEZ-LLUESMA \\ IESE Business School \\ University of Navarra, Spain \\ DIANE E. BAILEY \\ School of Information \\ University of Texas at Austin
}

We gratefully acknowledge the research assistance of Mahesh Bhatia, Virginia Buendia, Fabrizio Ferraro, and Menahem Gefen. We thank the engineers who graciously allowed us to observe them at work and who shared their thoughts with us. This research was made possible by National Science Foundation grant IIS 0070468. The General Motors-Stanford Work Systems Laboratory and a Stanford Graduate Fellowship provided additional funding. 


\title{
A “Knowledge Profile” of an Engineering Occupation: Temporal Patterns in the Use of Engineering Knowledge
}

\begin{abstract}
Each engineering occupation is distinguished by the body of specific knowledge it has built up over time. Some scholars argue that the instrumentality of this historically established knowledge in the solution of everyday design problems renders formal education more important than experience. Other scholars counter that engineering work primarily demands practice-generated knowledge that individuals construct in the course of everyday activities. We address this argument by documenting the frequency with which engineers apply different types of knowledge, with different derivations. Adopting a behavioral perspective, we isolated 1072 episodes of knowledge use in our field observations of structural engineers. From these episodes, we constructed a "knowledge profile" that indicated that two-thirds of the knowledge engineers employed was practice generated. The profile also revealed temporal patterns in the frequency with which the engineers used each knowledge type. Knowledge profiles like the one we constructed should help differentiate among engineering occupations, thereby serving as the foundation for conceptualizing occupations in a world of "knowledge work." In addition, knowledge profiles can help university engineering education programs better target and mirror the knowledge demands of the profession.
\end{abstract}

Keywords: knowledge types; engineering work; knowledge derivation 


\section{Introduction}

In the course of everyday work, engineers employ many types of knowledge. Some of this knowledge is specific to a particular occupation and universal among its members. The properties of wood, steel, and concrete, for example, are part of every structural engineer's knowledge repertoire; industrial engineers, meanwhile, are well versed in the dynamics of production systems, and hardware engineers are fluent in the functioning of gates, data arrays, and memory stores. Engineering occupations build up their distinct knowledge bases over time, codifying what they can in textbooks, design manuals, and standards. Bell argued that historically established knowledge of this type is so central to modern work that it renders formal education more important than experience. ${ }^{1}$ Scholars of engineering work concur, claiming that although day-to-day design problems may necessitate individual ingenuity, engineers primarily use the field's established knowledge to solve problems. ${ }^{2} 3$

Studies of engineers in the field, however, often tell a different story portraying historically established knowledge as secondary to knowledge that engineers generate in the course of practice. Building conceptually on the work of Suchman, ${ }^{4}$ Lave, ${ }^{5}$ and Henderson ${ }^{6}$ described how coordination and conflict among product designers occurred around collaboratively created drawings and sketches to such a large extent that these artifacts became the locus for situated, practice-generated knowledge. Similarly, Schön ${ }^{7}$ contended that models

\footnotetext{
${ }^{1}$ Bell, The Coming of Post-Industrial Society, 1973.

${ }^{2}$ Vincenti, What Engineers Know and How They Know It, 1990.

${ }^{3}$ Salvadori, Why Buildings Stand Up, 1980.

${ }^{4}$ Suchman, Plans and Situated Actions,1987.

${ }^{5}$ Lave, Cognition in Practice, 1988.

${ }^{6}$ Henderson, On Line and On Paper, 1999.

${ }^{7}$ Schön, The Reflective Practitioner, 1983.
} 
that portray professionals as problem solvers who map the present situation onto known problems and techniques are incomplete and misleading because they ignore the complexities of practice. The rational problem-solving paradigm falls apart, for example, when engineers address new problems that do not fit existing categories. In these instances, engineers engage in a reflective discourse involving diagnosis, experimentation, development, and design. Schön argued that because professionals work in environments characterized by uncertainty and uniqueness, they must generate substantial knowledge in the course of everyday activities.

Despite calls for studies of engineering to pay attention to the kinds of knowledge that engineers employ, ${ }^{8}$ few studies have conducted detailed investigations of knowledge use in everyday engineering. As a result, the question of whether historically established or practicegenerated knowledge is more instrumental in engineering work remains unresolved. From a theoretical viewpoint, knowing the answer to this derivation question would help situate engineering occupations with respect to each other and to other technical fields. For example, studies of technicians have shown that their heavy reliance on knowledge they derived from their everyday interaction with materials and people distinguished them from other occupational groups with which they worked, such as scientists, whose knowledge was more formal. ${ }^{9}{ }^{10}$ In short, understanding each occupation's relationship to knowledge and its derivation may help explain patterns of such workplace behaviors as information seeking, helping, and mentoring, as well as relationships of power and status. From an educational standpoint, information about the relative importance of historically established versus practice-generated knowledge in engineers’

\footnotetext{
${ }^{8}$ Donovan, “Thinking About Engineering,” 1986.

${ }^{9}$ Barley, “Technicians in the Workplace,” 1996.

${ }^{10}$ Orr, Talking About Machines, 1996.
} 
daily work would more empirically ground the debate about the appropriateness of the current, theory-heavy university engineering program and whether reform is needed.

In the context of engineering occupations, differentiating among types of knowledge according to their subject matter, not just their derivation, may provide additional benefits. Several scholars have developed taxonomies of engineering knowledge. Drawing from case studies of aeronautical engineering between 1900 and 1950, Vincenti outlined six types of engineering knowledge ranging from theoretical tools and quantitative data to the more hands-on domain of design instrumentalities. ${ }^{11}$ Similarly, Faulkner ${ }^{12}$ and Cross and Sivaloganathan ${ }^{13}$ detailed types of knowledge that engineers employ in product design innovation. Their lists contained some items quite similar to those on Vincenti’s list, such as design instrumentalities and stakeholder requirements, while adding types of knowledge that centered on aspects specific to product design, such as new product ideas, experimental procedures, legislation, and countryspecific product requirements. Documenting the frequency of engineers' use of these different types of knowledge would add depth and richness to theoretical understanding of how to distinguish engineering from other fields and practical ideas of how to educate engineers.

The project structure of engineering work shapes how engineers' use of knowledge might best be captured and represented. Engineering work is typically organized as projects and staffed by teams that work together for months or years. ${ }^{14}$ Projects often have specified stages with clear milestones and associated deliverables. For example, in structural engineering, projects have four industry-standard phases that reflect increasing sophistication and detail in design drawings,

\footnotetext{
${ }^{11}$ Vincenti, What Engineers Know and How They Know It, 1990, p. 208.

${ }^{12}$ Faulkner, “Conceptualizing Knowledge Used in Innovation,” 1994.

${ }^{13}$ Cross and Sivaloganathan, “Specialist Knowledge Identification, Classification, and Usage,” 2007.

${ }^{14}$ Loch and Terwiesch, "Communication and Uncertainty in Concurrent Engineering,” 1998.
} 
calculations, and models over time. Moreover, in many engineering projects, a different set of actors is involved during each stage or phase. The project organization of work suggests that different types of knowledge may be required at different points in time, perhaps by different people. ${ }^{15}$ For example, at the beginning of a project, design concepts would seem likely to predominate, whereas at the end of projects, construction or manufacturing issues may figure heavily.

In short, an accurate portrayal of engineers' knowledge use would need to provide a record of the types and derivation of knowledge that engineers employ over the course of a project, or what we call a "knowledge profile" of an engineering occupation. Such a profile would, for example, make clear how often engineers require knowledge of theoretical constructs from math, science, or engineering versus knowledge of product configuration and functioning. It would also reveal changes in the relative frequency of use of each type of knowledge that occurs as a project progresses.

We develop in this paper exactly such a knowledge profile for an engineering occupation based on close, careful observation of engineers at work. Studying engineers' knowledge use in situ, however, raises a host of challenges, the main one being how to identify when engineers actually employ knowledge in the course of their everyday activities. To confront this challenge, we adopted a behavioral perspective of knowledge.

\section{A Behavioral Perspective of Knowledge}

\footnotetext{
${ }^{15}$ Mer, “The Structural Engineer in the Design Office,” 2003.
} 
In our behavioral approach, we drew heavily on the work of social psychologist Roger Barker. ${ }^{16}$ Barker devised a method for documenting the "stream of behavior" of subjects that involved following them throughout the course of a day while recording meticulously all of their behaviors. Barker's close and extensive observations of subjects resembled participant observation, a practice commonly employed by researchers conducting ethnographic studies. In analyzing his data, however, Barker veered from traditional ethnography in that he did not take an emic approach that sought to understand the meanings that subjects held regarding their own actions. Rather, Barker took an etic approach in that he sought to systematically describe larger patterns of behavior that emerged from discrete actions and interactions. To achieve this end, Barker and his associates parsed a subject's stream of behavior into "behavioral episodes," or distinct units of analysis whose frequency they could count. Employing such an approach in multiple contexts enabled these researchers to determine emergent patterns of behavior from discrete actions and to make comparisons across settings.

Barker's focus was not knowledge, but more recent scholarship makes the case for the behavioral study of knowledge in situ. Researchers of situated cognition have shifted the target of studies of knowledge from the individual brain to the social realm. ${ }^{17}{ }^{18}$ These scholars view knowledge not as encoded information, or "knowing what," but as "knowing how" to act in a particular social setting. In the situated paradigm, individuals gain and demonstrate knowledge through participation in social practice. Similarly, the paradigm of distributed cognition draws attention to the central role of artifacts and tools, which relieve the cognitive burden on individuals by storing explicit and implicit knowledge or otherwise aiding cognition through

\footnotetext{
${ }^{16}$ Barker, The Stream of Behavior, 1963.

${ }^{17}$ Lave and Wenger, Situated Learning, 1991.

${ }^{18}$ Brown and Duguid, “Organizational Learning and Communities-of-Practice,” 1991.
} 
their use. ${ }^{19}$ Engineering manuals, textbooks, analysis software packages, and repositories of engineering drawings are examples of artifacts and tools that help individual engineers think at work.

In sum, a perspective of knowledge as participation in practice among colleagues, supported by tools, artifacts, and social interaction, justifies a research approach that documents knowledge through behavioral observation of individuals in their "natural" social setting. Engineering lends itself to studying knowledge in this manner because formal knowledge, collaborative problem solving, and a wide array of knowledge-supporting tools and artifacts are integral to engineering practice. ${ }^{20}{ }^{21}$ Thus, we followed Barker by focusing on observable actions that signaled the explicit use of knowledge and then analyzing those actions according to a set of characteristics that we specified.

For all the advantages a behavioral perspective of knowledge provides, this approach will miss some knowledge use; for example, it will fail to capture knowledge use when engineers sit in silent reflection. Yet, because engineers spend a large amount of their time interacting in clear and explicit ways with artifacts or colleagues, as our field observations confirmed, a behavioral perspective can produce a largely representative picture of the knowledge they employ. In our case, this approach yielded a wealth of quantifiable data that we could characterize in terms of features, such as type of knowledge employed, to build a knowledge profile of engineering knowledge.

\footnotetext{
${ }^{19}$ Hutchins, Cognition in the Wild, 1995.

${ }^{20}$ Vincenti, What Engineers Know and How They Know It, 1990.

${ }^{21}$ Henderson, On Line and On Paper, 1999.
} 


\section{Methods}

Research Setting

Structural engineering work. Among the many engineering disciplines, we chose to study structural engineering. One advantage of this choice for this study is that the work of structural engineers centers on objects easily comprehended by non-engineers (e.g., beams, buildings, bolts). Structural engineering is also a discipline with an established base of formal knowledge that is well documented in manuals and building codes and that continues to inform everyday practice. Additionally, the work of structural engineers involves considerable observable activity in the course of design, including drawing, consulting past project documents, measuring, performing calculations, constructing models, handling devices and materials, examining manuals and building codes, negotiating, launching software applications, and reporting results in person to managers.

The engineers we observed designed the structures that support buildings. They specified the materials, shapes, and sizes for all elements (e.g., beams, braces, piers) in the structural systems that prevent buildings from collapsing. The engineers worked on projects for individual clients or owners. A client or owner hired an architect, who in turn accepted bids from contractors and an array of engineering firms (e.g., soil, mechanical, electrical) to complete the project team.

Sites. We observed structural engineers at three firms in the San Francisco Bay area. Two firms employed twenty-five to thirty engineers during the time of our study. One of these two firms specialized in seismic upgrades; the other firm designed single-story fabrication plants for the computer industry. The third firm employed about twelve engineers across three offices 
during the time of our study; the particular office that participated in our study employed four engineers and specialized in multistory steel commercial buildings.

We organized our research team and fieldwork schedule to meet the challenges of studying knowledge in work. Local contexts (the company and the project) are critical to understanding the knowledge being used. To allow ample opportunity to delve into these contexts, we completed almost all observations at one site before moving on to the next. To reduce the possibility that technological advances might radically alter the nature of knowledge as we progressed across sites, we employed multiple observers, which compressed the time it took to complete our observations.

Participants. Across the three firms, we shadowed nineteen structural engineers as they worked on everyday tasks. These engineers often worked alone, but they also interacted regularly with colleagues to solve a technical problem or to plan work, which meant that we also captured knowledge use by many other engineers beyond these nineteen informants. To maintain a focus on engineering rather than management tasks, we targeted junior engineers (defined as those with less than seven years of work experience) and mid-level engineers (with seven to fifteen years of experience). We did not shadow recently hired engineers, who might not be familiar with work technologies and practical methods. Most of the engineers we observed held masters' degrees in structural engineering, a level of education typical in this industry. All told, we shadowed one senior (with more than fifteen years of experience), five mid-level, and thirteen junior structural engineers. Although we shadowed only one senior engineer, we had many opportunities to observe other seniors because they frequently interacted with the junior and mid-level engineers we were shadowing, providing us many opportunities to witness the knowledge used by the most experienced engineers in design tasks. 


\section{Data Collection}

We conducted observations from the summer of 1999 through the winter of 2001. Two authors and three research assistants conducted the observations. Each observation lasted on average from two to four hours, for a total of 238 hours across eighty-four observations. To prepare ourselves to make sense of knowledge use in what we saw and heard in the observations, we took steps to educate ourselves about the work. Early in the study, a working engineer not in our sample and a masters-degree student in civil engineering tutored us on products, tools, and design activities. We also read civil engineering texts and the first author took civil engineering classes.

To document the observations, we collected a rich set of data that captured the stream of an engineer's behavior. We wrote extensive field notes during each observation and audio taped engineers whenever they had extensive conversations with colleagues. We transcribed all audiotapes and inserted the dialogues into the field notes at the point where they occurred. We also gathered copies of documents employed by the engineer, including calculation sheets, drawings, spreadsheets, modeling graphics, and email. Altogether, we supplemented our field notes with more than 400 documents. These documents served as records of work and traces of thought processes. The engineers' calculation sheets, for example, in conjunction with our notes often explicated which values were assumed, which were determined by field inspection, which were taken from a design manual, and which were derived in the modeling process. Construction of such detailed final field notes took two to three days per observation. One author reviewed all final field notes to ensure thoroughness and consistency across observers.

Other data collection techniques helped us understand more broadly the work activities we observed. We interviewed a senior manager at each site to learn more about policies, 
practices, clientele, and technologies particular to that site. As necessary, we briefly interviewed engineers after observing them if we required explanation of an event or action that we did not understand in the course of our observation. We also attended several office meetings, for example one to discuss a technology purchasing budget. On two occasions, the first author traveled by plane with senior structural engineers from one of our study firms to construction sites, where the engineers met with architects and contractors before inspecting construction work in progress. The understanding we gained from these other data collection techniques informed our interpretation of our observations.

\section{Data Analysis}

We chose as the unit of analysis an episode of knowledge use. We separated these episodes from the stream of behavior recorded in the field notes via cues that signaled their beginnings and endings. Some cues were physical, as when an engineer reached for a building code manual, opened it to a particular page, placed her finger against a column of numbers, and copied a particular value onto her calculation sheet. Here, the opening cue was the reach for the book. Other cues were verbal. In a project meeting, for example, an engineer might claim that the key to answering a client's questions lay in how a certain timber beam would take a stain, causing someone to remember a cache of stain samples in a back room from a previous project. A member of the group would be dispatched to retrieve the samples, whose shades the group would examine to resolve the design issue.

In all cases, episodes ended when the engineer's use of the knowledge ended, which meant that episodes could be quite long (say, if an engineer repeatedly considered values from a particular table in a manual over the course of an afternoon) or quite short (if, instead, he only looked at the table once and moved on). We counted as a single episode the use of any particular 
kind of knowledge in relation to a particular problem; we did not count multiple episodes if the engineer turned to more than a single resource for the same kind of knowledge in the context of the same problem. In other words, the relevant object was the knowledge, not the artifact that may have held it. As a result of these decisions, our counts reflect frequency of knowledge use, not duration of knowledge use or frequency of artifact use.

We counted as episodes only the engineers' explicit use of knowledge. That is, we did not infer (or count) the use of knowledge that was automatically implied by virtue of an engineer carrying out a particular task (e.g., when an engineer drew a beam in AutoCAD, it implied that she knew how to use the software as well as how to draw a beam). That engineers routinely used such knowledge was without question, but to attempt to count each such use would have rendered analysis intractable.

For each episode of knowledge use, we determined three attributes key to this study: 1) the type of knowledge used in the episode, 2) the derivation of that knowledge, and 3) the project phase in which the incident occurred. Each attribute could take on a range of possible values (e.g., four phases of a project). Each value became a code (described below) that we could subsequently assign to the episodes in our field notes. Thus, we coded each episode with three values, one each for knowledge type, knowledge derivation, and project phase.

Our descriptions below are intended to differentiate one code from the other; these are illustrated by examples from our field notes. To further clarify, and to provide a sense of what we counted as an episode of knowledge use, we include Table 1, which features an excerpt of dialogue from our field notes in the left column and an explanation of the knowledge episodes within it in the right column. 


\section{Table 1. Excerpt of Dialogue from Field Notes with Knowledge Episodes Explained}

This excerpt is part of a design conversation among three engineers that lasted for two and a half hours and whose transcription ran more than seven pages of single-spaced text. The design problem facing the engineers concerned a cantilevered beam hanging in front of an elevator opening. When originally determining the depth of the beam, the engineers had failed to consider the fireproofing requirement, which would add three inches to the beam's depth. The engineers feared that the extra inches would cause the beam to hang too low in front of the elevator. In this excerpt, they tried to determine if their fear was warranted and, if so, how to alter the design to resolve the problem. The conversation occurred in the contract documents phase of the project, the third of the four standard phases.

\begin{tabular}{|c|c|}
\hline Dialogue & Knowledge Episode \\
\hline $\begin{array}{l}\text { Dan: [Dan has just been told a tab sticks out near the } \\
\text { beam that hangs in front of the elevator.] So add } 5 \\
\text { inches [for the tab]. Say } 8 \text { inches clear to center. } \\
\text { [He punches numbers into his hand calculator and } \\
\text { reads out loud the result.] So } 16 \text { times } 8 \text { divided } \\
\text { by } 27 \text { equals } 4.7 \text { equals t times } 6 \text { so t equals } .77 \text {. }\end{array}$ & $\begin{array}{l}\text { Dan shows knowledge of theoretical } \\
\text { tools* in rendering the formula for } \\
\text { "t," reflecting historically } \\
\text { established knowledge. This episode } \\
\text { and all others in this excerpt were } \\
\text { also coded for project phase contract } \\
\text { documents. }\end{array}$ \\
\hline $\begin{array}{l}\text { Tim: Well, how many overestimates did you make? So } \\
3 / 4 \text { might work. }\end{array}$ & $\begin{array}{l}\text { Tim shows practice-generated } \\
\text { knowledge of rules of thumb and } \\
\text { estimates when he recognizes that } \\
\text { Dan's calculation involved numerous } \\
\text { high estimates, whose combination } \\
\text { might inflate the result. He suggests } \\
\text { that rounding from } .77 \text { to } .75 \text { should } \\
\text { thus be fine. }\end{array}$ \\
\hline $\begin{array}{l}\text { Dan: [He points on the drawing.] Let's make this } 7 . \\
\text { Make that } 3 / 4 \text { inch. That should work. This is the } \\
\text { moment connection you talked about. We're } \\
\text { cantilevered over the plate. My moment is } 16 \\
\text { times } 8 \text { divided by, well, } 8 \text { kips is my load. That's } \\
\text { why I like this connection...stroke of genius } \\
\text { coming up with this collector. What was that } \\
\text { reaction over there? [Again he uses his } \\
\text { calculator.] } 24 \text { times .19 times } 5 \text {...17 kips. } \\
\text { Approximately twice as much as there. You can }\end{array}$ & $\begin{array}{l}\text { Dan again shows knowledge of } \\
\text { theoretical tools when he essentially } \\
\text { defines moment, but we do not count } \\
\text { this use as a separate episode because } \\
\text { it occurred in the context of the same } \\
\text { problem. }\end{array}$ \\
\hline
\end{tabular}




\begin{tabular}{|c|c|}
\hline $\begin{array}{l}\text { use this as a shear connection, as a moment } \\
\text { connection...so it must be big enough to clear the } \\
\text { bolts. Once we cantilever out, what's the } \\
\text { connection to that? If it is a plate, we lose our } \\
\text { connection again unless we use } 1 / 2 \text { inch shims. } \\
\text { What do you think? [No one responds.] I'd go } \\
\text { with shims. That's a healthy connection. The third } \\
\text { connection here is exactly the same but reversed. }\end{array}$ & $\begin{array}{l}\text { knowledge of appropriate } \\
\text { structural elements from this point } \\
\text { to the end of this excerpt. He notes } \\
\text { here that they can use } 1 / 2 \text { inch shims } \\
\text { to avoid losing the connection; later } \\
\text { he will select a TS, a W8 and bolts to } \\
\text { complete the design. }\end{array}$ \\
\hline \multicolumn{2}{|l|}{ Jen: That's typical, no? } \\
\hline $\begin{array}{l}\text { Dan: No. These two tie into here, a steel to steel } \\
\text { connection, a TS coming into a W8 by } 24 \text {. That's } \\
\text { non-typical. [He draws on the plan view of the } \\
\text { hard copy drawing before them.] Ok, this is the } \\
\text { picture we need. }\end{array}$ & $\begin{array}{l}\text { Dan displays practice-generated } \\
\text { knowledge of design } \\
\text { instrumentalities in recognizing that } \\
\text { the connection is not typical and will } \\
\text { thus require a separate drawing to } \\
\text { make the details of the connection } \\
\text { clear for others (e.g., contractor, } \\
\text { fabricator, peer reviewer). }\end{array}$ \\
\hline \multicolumn{2}{|l|}{$\begin{array}{l}\text { Jen: [She points on the drawing.] You're saying this } \\
\text { tab, then a plate against this weld? }\end{array}$} \\
\hline $\begin{array}{l}\text { Dan: Yes. [He directs his next comment to Tim.] You } \\
\text { have a sketchpad? [Dan now begins to draw a } \\
\text { series of details on Tim's white grid pad.] Over } \\
\text { here, a TS. The W8 is going to be off so edge of } \\
\text { deck is here and face of the core is here. There's } \\
\text { my first connection to the core. }\end{array}$ & $\begin{array}{l}\text { Here Dan continues with his } \\
\text { knowledge of appropriate structural } \\
\text { elements, which we do not count as a } \\
\text { separate episode because the problem } \\
\text { is unchanged. }\end{array}$ \\
\hline \multicolumn{2}{|l|}{ Jen: I don't think you can fit two.... } \\
\hline \multicolumn{2}{|l|}{ Dan: Oooohhh... } \\
\hline \multicolumn{2}{|l|}{ Jen: 4 inch on the center work. } \\
\hline \multicolumn{2}{|l|}{ Dan: Do we have a bolt in the office? [Tim gets up.] } \\
\hline $\begin{array}{l}\text { Jen: [She directs Tim.] In the library. [She addresses } \\
\text { Dan.] But clearance is } 3 \text { inches right? } 3 \text { inches } \\
\text { times the diameter of the bolts? }\end{array}$ & $\begin{array}{l}\text { Jen shows established knowledge of } \\
\text { quantitative data in her recall of the } \\
\text { value of the clearance requirement }\end{array}$ \\
\hline
\end{tabular}




\begin{tabular}{|l|l|}
\hline $\begin{array}{l}\text { Dan: I think the practical limitation is getting in here to } \\
\text { make the weld. }\end{array}$ & $\begin{array}{l}\text { for the fireproofing material. } \\
\text { knowledge of construction } \\
\text { feasibility and ease when he notes } \\
\text { that there is no room for the welder's } \\
\text { hand to make a weld, knowledge that } \\
\text { he continues to use in the design } \\
\text { session past this excerpt. This } \\
\text { knowledge is practice-generated. }\end{array}$ \\
\hline $\begin{array}{l}\text { Dan: [Tim returns with a small clear plastic box } \\
\text { containing a few bolts and hands Dan a massive } \\
\text { bolt about } 1 \text { inch in diameter and } 2 \text { inches long.] } \\
\begin{array}{l}\text { We need a nut. We need a nut and a bolt. Have a } \\
\text { nut in there? [Jen and Tim leave in search of a } \\
\text { nut.] }\end{array}\end{array}$ \\
\hline
\end{tabular}

*Bold text reflects the codes that we applied for each knowledge episode.

Knowledge type. Our initial reading of our field notes and our experiences while conducting observations suggested to us that we could take as a starting point Vincenti’s knowledge typology, ${ }^{22}$ whose absence of knowledge related to the design of manufactured products made it a better fit for structural engineering than the taxonomies by Faulkner ${ }^{23}$ or Cross and Sivaloganathan. ${ }^{24}$ We did, however, need to translate Vincenti's typology, built in the context of aeronautical engineering, into structural engineering terms, an effort that yielded specific descriptions of six knowledge types: structural systems criteria, fundamental design

\footnotetext{
${ }^{22}$ Vincenti, What Engineers Know and How They Know It, 1990.

${ }^{23}$ Faulkner, “Conceptualizing Knowledge Used in Innovation,” 1994.

${ }^{24}$ Cross and Sivaloganathan, “Specialist Knowledge Identification, Classification, and Usage,” 2007.
} 
concepts, theoretical tools, design instrumentalities, quantitative data, and rules of thumb and estimates. We provide those descriptions here, with examples culled from our field notes to illustrate how use of each type was behaviorally manifested in our field notes (and thus permitted coding).

1. Structural systems criteria. Structural systems criteria referred to the constraints placed on the engineer's design of the building structure. Engineers translated the economic or functional objectives of architects and owners, often stated in qualitative terms, into broad technical criteria that served to pare down the list of possible design solutions. For example, a senior engineer whom we observed displayed knowledge about structural systems criteria when he explained to a junior engineer the various issues that constrained the redesign of a multistory mall. He translated the architect's objective (removing a wall on the lower floors), the owner's preference (to minimally disrupt existing tenants during construction), and the city’s requirement (that the same wall must remain on the upper floors) into structural criteria that necessitated first stabilizing and then cutting the wall on the lower floors.

2. Fundamental design concepts. The set of elements available to the structural engineer was quite large and varied along multiple factors, including an element’s material (e.g., steel or wood posts) and its shape (e.g., flanged or tubular beams). Knowledge of fundamental design concepts comprised a general awareness of these various forms as well as the function of each element. Knowledge of fundamental design concepts concerned knowing the normal configuration, operation, and performance of elements such as posts, beams, and welds independent of context. A junior engineer working on a renovation project employed knowledge of fundamental design concepts when he noted that certain elements in the existing structure could not operate as “collectors.” The elements failed in this role because they were not designed 
to gather seismic loads from the surrounding elements and distribute them to outer walls. The engineer's explanation, essentially the definition of a seismic collector, reflected his knowledge of the function of this standard element.

3. Theoretical tools. Structural engineers employed a considerable number of theoretical tools covering a broad spectrum of topics. Theoretical tools included basic concepts such as tension (the force imposed on an element when pulled by its ends) and compression (the force imposed on an element when pushed on its ends). Simple mathematical formulas (e.g., $\mathrm{M}_{\max }=$ $\mathrm{wl}^{2} / 8$, which expresses a beam's maximum moment, $\mathrm{M}$, in terms of the beam's width, $\mathrm{w}$, and length, l) as well as more complex models of structural behavior were also theoretical tools. A senior engineer employed knowledge of theoretical tools when he helped a junior engineer interpret the results of an analysis program. He asked her to consider whether the beam in question would experience tension or compression, given that it was the only horizontal component in her model and was under gravity loads. He expected her to answer his question based on her knowledge of tension, compression, and the principle of equilibrium, not on the output of the computer program, whose confusing result he suspected was blinding her to basic relationships.

4. Design instrumentalities. Design instrumentalities comprised knowledge of the procedures, ways of thinking, and judgmental skills required to carry out the work of engineering design. Design instrumentality was evident in drawing, which involved thinking visually, seeing in three dimensions while reading and drawing in two, and presenting information visually and in a logical manner. Design instrumentality also arose in the context of selecting and using technologies as well as knowing how to solve problems and develop models. A junior engineer displayed design instrumentality when he attempted to calculate prestress losses in concrete 
using an analysis software package. ${ }^{25}$ He was stalled in his efforts when the menu button for this option appeared lightly shaded in gray, indicating that it could not be selected. He wondered if the button was gray because his firm had not paid for that module or if the program somehow automatically calculated prestress losses, making the button's selection unnecessary. Finding neither software documentation nor a knowledgeable peer, the engineer solved the riddle by working backwards from a known solution, using his hand calculator to confirm what was happening in each step of the computer program.

5. Quantitative data. Structural engineers used a considerable amount of quantitative data, which they primarily employed in calculations and mathematical analyses. A junior engineer used quantitative data when designing collectors to transfer roof loads to building columns, which required knowing the precise value for the stiffness of a particular metal decking. Lacking this knowledge offhand, the engineer retrieved a 1979 deck manufacturer's catalog from her firm's small library. Because the project involved the retrofitting of a building constructed in 1984, she commented that perhaps she should have examined the 1982 catalog, but she suspected the numbers had not changed much between the two versions.

6. Rules of thumb and estimates. Some knowledge that structural engineers employed consisted of rough, ballpark figures and shortcut practices that allowed them to move forward in their work absent exact or precise values. An engineer employed such knowledge when he noted that, in general, a building over 300 feet wide requires expansion joints (narrow separations) in the concrete to permit it to shrink and expand. In another example, an engineer separated his

\footnotetext{
${ }^{25}$ Concrete that is reinforced with steel bars can be placed in compression even before loads are applied to it by prestressing the concrete. Prestressing may be accomplished by tensioning the steel bars before the concrete hardens. After such treatment, factors like shrinkage in the concrete may decrease the stress that has been induced, resulting in prestress losses.
} 
thumb and forefinger to help him guess that a thickness of an inch or two would be fine for a pane of glass in a proposed skylight.

While reading our field notes in the course of translating Vincenti's scheme into structural engineering terms, we determined that his six knowledge types could not describe the full range of knowledge use that we observed. We detected four types of knowledge that Vincenti's framework did not cover: appropriate structural elements, construction feasibility and ease, organization of work, and engineering actors.

1. Appropriate structural elements. Engineers faced myriad decisions about the specific elements to employ as they began to design each structure. Elements had distinct physical features, properties, and industry-standard names. There were many different types of elements beams, columns, trusses, bolts, and welds, to name just a few - with many variations within each type. Faced with this incredible variety, the engineer had to interpret the system criteria to select those structural elements that were best suited to the specific situation. A junior engineer displayed such knowledge when he explained to a peer that he first had employed multiple studs (timber boards) bound together, but then had replaced them with a steel beam shaped like a square tube. Because the tube-like beams lay at an angle, he further decided it was "probably best” to use a wide-flange beam (whose cross-section looks like a capital “I”) above the tube-like beams. In deciding to use steel beams rather than wooden studs and wide-flange beams placed above tube-like ones, this engineer relied upon knowledge of appropriate structural elements to create a design that best suited the confluence of requirements for this structure.

2. Construction feasibility and ease. Structural engineers' designs were constrained by codes and theory but were not completely determined by them. Also factoring into design decisions was the engineer's knowledge of the feasibility and ease of construction, or the degree 
to which the design was practical and easily accomplished on the construction site. A senior engineer displayed this kind of knowledge when he described to a junior engineer how a tube steel beam would be cut and welded at its base. As they talked, the engineers envisioned and even imitated carrying out construction actions, suggesting the physical, tactile, and kinesthetic aspects of this knowledge.

3. Organization of work. Knowledge of how structural engineering work was or should have been organized appeared in many forms. Part of this knowledge, but certainly not all, falls under the rubric of traditional project management. Junior engineers, who were rarely involved in project management, used knowledge of work organization when organizing their own tasks, often drawing on knowledge about the phases and timing of projects. A senior engineer displayed such knowledge when he remarked to a junior colleague that they needed geotechnical information to confirm the schematic design for a project in its early stages, but not time history information, which could wait until a later phase and ought to go out under a peer review contract.

4. Engineering actors. Structural engineers developed personal knowledge about other parties, especially those external to the firm, including owners, architects, other engineers, contractors, steel detailers, and peer reviewers. Knowledge of engineering actors encompassed how these parties accomplished their work, how they construed the world, what their objectives were, and what responsibilities they shouldered. This type of knowledge included knowledge about other professionals in general, as when a senior engineer noted that architects typically appreciated fewer columns. A large part of it, however, consisted of knowledge about particular people, as illustrated when a senior engineer remarked that a certain owner tended to micromanage details. 
Derivation of knowledge. The knowledge that engineers employed was either historically established or practice-generated. Through mathematical, scientific, or engineering analysis and experimentation, researchers, academics, and early practitioners over the years have generated the field's historically established knowledge, which forms the profession's formal knowledge base. An example of historically established knowledge that we observed in use was the amount of load that a steel beam of a certain depth and weight per linear foot could withstand before buckling. Engineers often retrieved established knowledge from design manuals and building codes; established knowledge also comprised the bulk of what they learned in university courses. In all cases, historically established knowledge was preexisting knowledge for the engineers who employed it, in the sense that neither they nor their colleagues created it.

Unlike established knowledge, which was typically universal, practice-generated knowledge was often (but not always) context-specific because working engineers constructed it in the course of their everyday activities. ${ }^{26} \mathrm{~A}$ junior engineer displayed practice-generated knowledge when he explained to a colleague how he determined the number of beam categories to create when sizing beams for a building design (i.e., when determining the beams' depth and weight per linear foot): Fewer categories saved costs through economies of scale in ordering, but grouping small beams in a category with larger ones meant paying for beams that were stronger than necessary. Thus, a balance had to be struck in deciding the right number of beam categories;

\footnotetext{
${ }^{26}$ The distinction between historically established knowledge and practice-generated knowledge is not meant as a reformulation of the explicit-tacit knowledge dichotomy. Although all historically established knowledge that we encountered was explicit, not all practice-generated knowledge was tacit. Polanyi (The Tacit Dimension, 1966) defined tacit knowledge as knowledge that cannot be articulated. Engineers in our study routinely voiced their practice-generated knowledge to themselves and to one another. They mumbled as they created models, they asked for and received help and explanations from others, and they tackled thorny issues side-by-side in design conversations that could last minutes or hours. Rarely did the engineers appear to have difficulty articulating their knowledge.
} 
the engineers achieved this balance with a rough calculus that varied according to the particulars of a project rather than with a standard formula.

We did not require that the engineer generate by himself the practice-generated knowledge he employed. For example, one engineer employed a matrix of values that his colleague had created and stored in a spreadsheet for use by others in the firm. Although the knowledge in the matrix was recorded and hence preexisting, it was not historically established because it was particular to the firm's client base, its geography and its work practices, rendering it of little value to others in the profession. In general, the situated nature of practice-generated knowledge limited its distribution across firms.

One might guess from the outset that some types of knowledge would tend to be historically generated while others would tend to be practice generated; however, we did not determine derivation in the abstract. Instead, we investigated each episode on its own terms, independently determining from the context as well as the engineer's behavior, speech, and artifact use whether she was drawing that knowledge from the established knowledge base or from work, be it her own or that of colleagues. Among other benefits, this practice allowed us to discover, rather than assume, whether certain knowledge types tended towards one derivation or the other.

Project phase. Each episode occurred at some point in time that we could associate with one of four industry-standard phases of a project. In the schematics design phase, structural engineers illustrated for architects and owners alternative design options for each major system. Next, in the design documents phase, structural engineers created detailed drawings and calculations for the chosen option to aid contractors in the estimation of materials and construction ease. In the contract documents phase, engineers conducted the final design and 
analysis and recorded their results in documents that were presented to industry peer reviewers and local government plan checkers so that building permits could be issued. In the final phase, construction management, structural engineers handled construction issues and reviewed drawings from steel fabricators to ensure that they matched the structural design. Coding for project phase was straightforward because the engineers explicitly told us the project phase of their work in every observation. Project phases provided a systematic framework for conducting temporal analyses of our data.

Two authors developed our final list of codes, with code descriptions, as well as precise guidelines for identifying and coding episodes of knowledge use. They accomplished this task via an iterative process, during which they coded the same set of field notes and then discussed their differences until they achieved consistency. They also met with key informants to solicit their feedback, validate the knowledge types, and obtain additional pointers to behaviors that would signal the use of each type of knowledge. Having participated in these activities and with the resulting list and guidelines in hand, one author then coded the full set of field notes, ultimately identifying and coding 1072 episodes of knowledge. To account for having more observations in the contract documents and construction management phases than in the other phases, we normalized the frequency of use of each knowledge type to the number of episodes per hour. We used the normalized data to create a knowledge profile of this occupation.

\section{A Knowledge Profile of Structural Engineering}

To assess differences in use across the many types of knowledge that structural engineers employed, we created a "knowledge profile" for this occupation. The profile indicates the frequency with which engineers employed each type of knowledge as they carried out their tasks and considers the derivation of the knowledge employed. The profile also addresses issues of 
possible temporal patterns associated with knowledge use by considering variation in frequencies of use over time, divided here into the chronological phases of an engineering design project.

Table 2 shows the frequency of use of each of the ten types of structural engineering knowledge in terms of the number of episodes per hour. Knowledge of design instrumentalities topped the list with a frequency of just under one episode per hour. Appropriate structural elements, engineering actors, and fundamental design concepts, each with frequencies greater than 0.5 episodes per hour, were the next most frequent, followed by organization of work and theoretical tools. Least frequent were construction feasibility and ease, rules of thumb and estimates, quantitative data, and structural systems criteria.

The particularly low result for structural systems criteria knowledge, at less than one episode per ten hours of observation, may have been, in part, a function of our research design: Knowledge of this type arose in conjunction with tasks that senior engineers, whom we did not target, typically carried out. This result also reflects, however, that engineers employed structural systems criteria knowledge primarily only in the first phase of engineering projects and then almost never again. Figure 1, which plots frequencies of use by project phase, shows this temporal pattern and indicates that other types of knowledge do not experience the same sharp decline and tailing off after the schematics design phase. 
Table 2. Frequency of Use of Structural Engineering Knowledge by Type

\begin{tabular}{|l|c|c|}
\hline \multicolumn{1}{|c|}{ Types of Structural Engineering Knowledge } & N & $\begin{array}{c}\text { Frequency of Use } \\
\text { (episodes/hr) }\end{array}$ \\
\hline Design Instrumentalities & 230 & 0.97 \\
\hline Appropriate Structural Elements & 179 & 0.75 \\
\hline Engineering Actors & 161 & 0.68 \\
\hline Fundamental Design Concepts & 141 & 0.59 \\
\hline Organization of Work & 104 & 0.44 \\
\hline Theoretical Tools & 90 & 0.38 \\
\hline Construction Feasibility and Ease & 62 & 0.26 \\
\hline Rules of Thumb and Estimates & 50 & 0.21 \\
\hline Quantitative Data & 37 & 0.16 \\
\hline Structural Systems Criteria & 18 & 0.08 \\
\hline Total & 1072 & 4.50 \\
\hline
\end{tabular}

Figure 1 reveals a number of other temporal patterns in knowledge use. Types of knowledge that reflected understanding of the physical components of the design solution and their interactions tended to peak in the two middle phases of projects (design development and contract documents), when work was centered on creating detailed drawings and conducting multiple calculations in the course of analyzing mathematical models of structural design solutions. Use of knowledge of design instrumentalities, appropriate structural elements, fundamental design concepts, theoretical tools, and quantitative data all followed this pattern. 
Figure 1. Frequency of Use of Structural Engineering Knowledge by Type and Project Phase

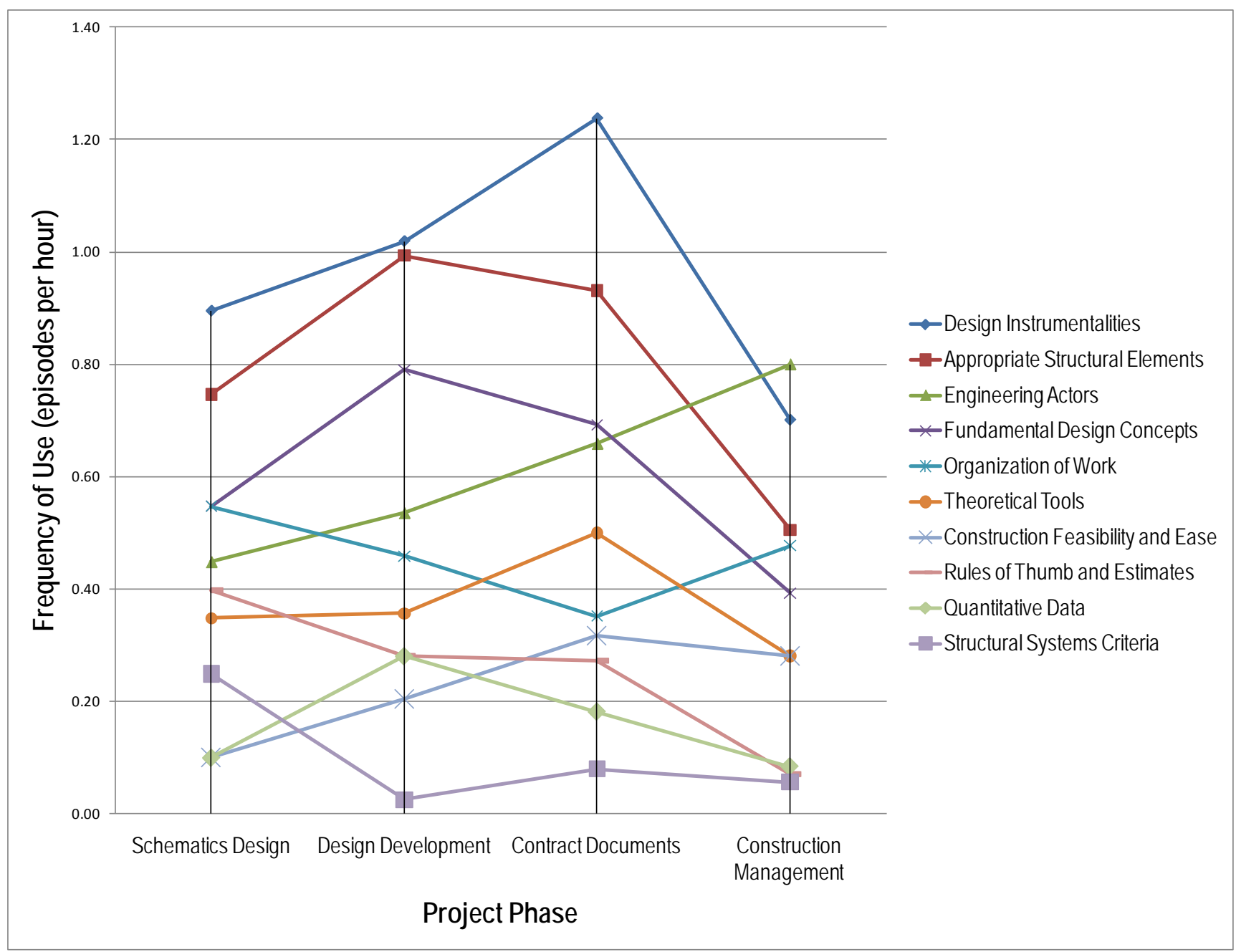


A different pattern appeared for use of knowledge types that reflected understanding not of physical components, but of the people who would design, construct, occupy, or own the completed building. Use of these types of knowledge - such as engineering actors, organization of work, and structural systems criteria - peaked at either the beginning or end of projects, when engineers engaged the most in interactions with architects, contractors, clients, and owners. For example, the pattern for use of knowledge of engineering actors, which peaked in the final project phase of construction management, reflected intense negotiating activity with contractors. Similarly, use of knowledge of structural systems criteria peaked in the first phase of schematics design because engineers employed it when negotiating with architects, clients, and owners over how to implement their vision. Overall patterns of knowledge use thus suggested that what mattered most for structural engineers in the middle of a project was understanding the physical components of the design and their interactions with each other; understanding people and their interpersonal interactions was instrumental primarily at the beginning and end of projects.

Two types of knowledge violated the overall pattern of knowledge of building components peaking in the middle phases of projects and knowledge of people affiliated with the building peaking at the beginning or end of projects. Use of rules of thumb and estimates peaked at the beginning of projects, primarily because ballpark calculations were sufficient to get a general sense of project costs for architects, clients and owners; engineers required more precise measures only later when carrying out detailed calculations in the course of building models. Use of knowledge of construction feasibility and ease, which peaked in the contract documents phase, remained nearly that high in the final phase of construction management because this type of knowledge was necessary during actual construction. 
Table 3 shows the derivation of knowledge as a percentage of episodes within each type. Fully two-thirds of all knowledge the engineers used was practice-generated. The predominance of practice-generated knowledge strongly suggests that recalling and applying historically established knowledge was insufficient to accomplish structural engineering work. Rather, this work entailed adapting existing knowledge to a series of often novel and complex situations, thus necessitating practice-generated knowledge.

Table 3. Derivation of Structural Engineering Knowledge by Type*

\begin{tabular}{|l|c|c|c|c|}
\hline \multirow{2}{*}{ Type of Structural Engineering Knowledge } & \multicolumn{3}{|c|}{ Derivation (as percentage of episodes) } \\
\cline { 2 - 5 } & $\begin{array}{c}\text { Historically } \\
\text { Established }\end{array}$ & $\begin{array}{c}\text { Practice- } \\
\text { Generated }\end{array}$ & Unclear & $\mathrm{N}$ \\
\hline Design Instrumentalities & $11 \%$ & $79 \%$ & $10 \%$ & 230 \\
\hline Appropriate Structural Elements & $4 \%$ & $94 \%$ & $2 \%$ & 179 \\
\hline Engineering Actors & $15 \%$ & $78 \%$ & $7 \%$ & 161 \\
\hline Fundamental Design Concepts & $72 \%$ & $18 \%$ & $10 \%$ & 141 \\
\hline Organization of Work & $8 \%$ & $89 \%$ & $3 \%$ & 104 \\
\hline Theoretical Tools & $60 \%$ & $11 \%$ & $29 \%$ & 90 \\
\hline Construction Feasibility and Ease & $0 \%$ & $95 \%$ & $5 \%$ & 62 \\
\hline Rules of Thumb and Estimates & $6 \%$ & $70 \%$ & $24 \%$ & 50 \\
\hline Quantitative Data & $\mathbf{5 9 \%}$ & $24 \%$ & $16 \%$ & 37 \\
\hline Structural Systems Criteria & $17 \%$ & $\mathbf{8 3} \%$ & $0 \%$ & 18 \\
\hline Total & $23 \%$ & $67 \%$ & $10 \%$ & 1072 \\
\hline
\end{tabular}

*Boldface type under derivation indicates the maximum percentage within each knowledge type.

The ratio of practice-generated knowledge to historically generated knowledge was highest in knowledge of appropriate structural elements and construction feasibility and ease, two types of knowledge that dealt heavily in the specifics of the particular structure under design. Because industry standards and the constraints of structural systems criteria rarely uniquely determined the appropriate structural elements to employ in a given design, the engineers’ 
experiences and preferences typically influenced their final selection of the "best" solution for each building. In short, practice strongly shaped the engineers' understanding of which elements worked best. Similarly, engineers acquired construction knowledge on visits to building sites and from discussions in the office, during which we often observed them gesturing in space to illustrate shapes and sizes and, as in the excerpt in Table 1, handling physical elements like bolts to determine the hand space needed for installation. Practice, not the field's accumulated knowledge, served as the unique source for engineers' knowledge of what could be achieved with ease on a given construction site.

The use of historically established knowledge outpaced that of practice-generated knowledge—in fact, dominated it—only among episodes involving the use of three types of knowledge: fundamental design concepts, theoretical tools, and quantitative data. These types of knowledge most directly dealt with universals (e.g., the normal configuration of a fillet weld or the load that a steel beam of a certain weight and thickness could bear) that did not vary by context. Engineers often turned to textbooks, manuals, building codes, and vendor catalogs that served as repositories of these types of knowledge. Each of these three types of knowledge peaked in the middle phases of projects, pointing to a temporal pattern for the use of historically established knowledge that largely followed an inverted U-shape.

We note that knowledge of theoretical tools presented the highest percentage of episodes (29\%) in which we could not determine the derivation of the knowledge. In these episodes, the engineers employed knowledge that we knew they did not construct while we were observing, but we could not confirm if the source of the knowledge was one of the many thick code books or manuals in the office or if the engineers had generated the knowledge at some earlier point. We do know, however, that the time pressures of completing project work under contracts and 
accepted bids meant that the engineers we observed had little free time to engage in the kind of experimentation or mathematical musings that would have generated substantial new knowledge of theoretical tools. Thus, the probability seems high that when they employed this type of knowledge, it was historically established.

\section{Theoretical Contributions and Implications}

We took as our starting point for this study Vincenti’s taxonomy of engineering knowledge, which he developed based on case studies of aeronautical engineering. ${ }^{27}$ We showed how his taxonomy could be translated into structural engineering terms, yielding six types of knowledge: structural systems criteria, fundamental design concepts, theoretical tools, design instrumentalities, quantitative data, and rules of thumb and estimates. In the course of analyzing observations of structural engineers at work, we discerned four other types of knowledge that the engineers routinely employed that Vincenti’s taxonomy did not reflect: appropriate structural elements, construction feasibility and ease, organization of work, and engineering actors.

Of the four new types of knowledge that we identified via our analysis of field observations of engineers at work, only one appears similar to any of Faulkner's ${ }^{28}$ or Cross and Sivaloganathan's types, ${ }^{29}$ whose taxonomies of engineering knowledge specifically targeted product design. Our construction feasibility and ease, which reflects knowledge of whether or not a structural design can be built, resembles Faulkner’s “production competence,” which includes understanding the design requirements for manufacture and the firm's competence in pilot (and later scaling up of) production. Knowledge of construction feasibility and ease also

\footnotetext{
${ }^{27}$ Vincenti, What Engineers Know and How They Know It, 1990.

${ }^{28}$ Faulkner, “Conceptualizing Knowledge Used in Innovation,” 1994.

${ }^{29}$ Cross and Sivaloganathan, “Specialist Knowledge Identification, Classification, and Usage,” 2007.
} 
resembles Cross and Sivaloganathan’s “manufacturing process capability and available materials," which reflects knowledge of what is achievable in manufacturing.

Given the similarity of our "construction and feasibility ease" to existing types in other taxonomies, the number of knowledge types newly identified in this study is reduced to three: appropriate structural elements (knowing which from among a vast variety of elements to employ given the specific criteria of a particular project), organization of work (knowing how to arrange and carry out project tasks, including one’s own work), and engineering actors (knowing how others construed the world and what their objectives were). The first of these three types concerns the physical components of building structures: it reflects an engineer's knowledge of the normal configuration of a large variety of structural elements and to assess their potential for serving the particular purpose of the current design.

The other two types of knowledge that we newly identified veer towards knowledge not of building components, but of people, a realm largely absent from prior taxonomies. Knowing how to organize work for the project team and oneself means being able to anticipate others' actions, demands, and desires in the course of carrying out interdependent tasks. Knowing about engineering actors means understanding not only traits of professional groups that one would encounter in the course of building design, but also traits of particular individuals within those groups. In identifying these two types of knowledge, we expand the depiction of the kinds of knowledge that engineering work requires.

We go further in our study, however, than simply establishing new types of knowledge that engineers employ. By adopting a behavioral approach that permitted methodical counts of engineers' use of each type of knowledge in the course of everyday work, we can speak directly to the question of how frequently engineers employed each type of knowledge. Thus, we can 
report that design instrumentalities were by far the most frequently employed type of knowledge, outpacing knowledge of theoretical tools by more than a factor of two, and knowledge of quantitative data, which was second only to structural systems criteria in infrequency of use, by more than a factor of six. By providing detailed explanations and examples of our methods, we leave open to future research the cataloguing of the frequency of knowledge use in other occupations and possible comparisons across occupations.

We also speak to the question of the importance of historically established versus practice-generated knowledge in engineering work. We found that practice-generated knowledge accounted for fully two-thirds of the knowledge that structural engineers employed, a finding that resonates with contentions by Henderson ${ }^{30}$ and Schön ${ }^{31}$ that, in general, engineers generate in the course of everyday activities most of the knowledge that they require. Still, this finding is surprising in structural engineering, a field with a large and enduring base of established knowledge. Engineers in fields whose knowledge becomes obsolete more rapidly than does knowledge in structural engineering (as, for example, certain branches of computer science) are likely to employ an even smaller percentage of historically established knowledge. Nonetheless, that historically established knowledge represented a third of the knowledge that structural engineers called upon in the course of their work activities lends some credence, at least in this occupation, to claims for its significance in everyday problem-solving.

By separately assessing for each episode of knowledge use the derivation of that particular knowledge, we were able to build up from our data, rather than assume from the

\footnotetext{
${ }^{30}$ Henderson, On Line and On Paper, 1999.

${ }^{31}$ Schön, The Reflective Practitioner, 1983.
} 
outset, that each knowledge type appears to be predominantly of one derivation or the other. Thus, for example, knowledge of design instrumentalities is predominantly practice-generated, whereas knowledge of fundamental design concepts is largely historically established. This finding provides grounded, empirical justification for roughly grouping knowledge types according to their derivation, with three types falling under the heading of historically established knowledge (fundamental design concepts, theoretical tools, and quantitative data) and the remaining seven types falling under the heading of practice-generated knowledge.

Finally, we show through our knowledge profile that the use of many types of knowledge fluctuates over the course of a project. This result resonates with the results of Cross and Sivaloganathan's study, ${ }^{32}$ which also noted variation in the use of different knowledge types across project phases. That study found that knowledge of country- or market-specific requirements, for example, was absolutely required during the first four of seven phases of product development, but only possibly required in the last three phases. Because those authors did not quantitatively measure the frequency of knowledge use, as we did, they could not provide plots like those in Figure 1 that depict exact, as opposed to approximate, variations in use of each knowledge type over time. Consequently, our work adds to the literature by permitting detailed comparison of temporal patterns across knowledge types, for example by noting that some knowledge types are employed more frequently in the middle phases of a project than the ends (e.g., design instrumentalities, appropriate structural elements) whereas other types exhibit the reverse pattern (e.g., construction feasibility and ease, structural systems criteria).

\footnotetext{
${ }^{32}$ Cross and Sivaloganathan, “Specialist Knowledge Identification, Classification, and Usage,” 2007.
} 
From a theoretical perspective, future studies employing taxonomies and methods similar to ours to build knowledge profiles of other engineering occupations would allow scholars to more accurately portray the epistemological requirements and characteristics of engineering's specialties. The heavy use, for example, of quantitative data and theoretical tools would signal a very different kind of engineering work than would a predominant use of rules of thumb and construction feasibility and ease. Similarly, an engineering occupation that demands a deep understanding of engineering actors might draw more upon psychological and sociological insights than would a field whose knowledge is dominated by theoretical tools. Such portrayals would not only help distinguish among engineering occupations, they could also help distinguish engineering occupations as a whole from related occupations, such as scientist and technician. The usefulness of such distinctions for theory lies in their potential to help explain engineering workplace dynamics - including role interactions, knowledge transfer, and the shaping of occupational hierarchies - that impact the quality of work processes and products.

More broadly, understanding "knowledge" work in general necessitates being able to discern what types of knowledge it requires, to what extent, and when. Knowledge profiles provide the analytical means for achieving that end. In fact, the Occupational Information Network (O*NET), which supersedes the seventy-year-old Dictionary of Occupational Titles maintained by the U.S. Department of Labor, includes knowledge as one of the main descriptors by which occupations are ranked. ${ }^{33}$ Thus, for example, civil engineering, of which structural engineering is one branch, ranks highest among all occupations listed in the O*NET in the importance that knowledge of engineering and technology plays in it; it ranks third in the

\footnotetext{
${ }^{33}$ See http://www.doleta.gov/programs/ONet/.
} 
importance of knowledge of design, and it ranks in the top twenty in the importance of knowledge of mathematics. However, the O*NET database places civil engineers $404^{\text {th }}$ in the importance that knowledge of customer and personal service plays in their occupation, behind tree trimmers, boilermakers, pipefitters, livestock managers, ship loaders, ceiling tile installers, freight inspectors, nuclear monitoring technicians, and animal trainers, among others. This contradiction with our findings, which point to the importance of knowledge of engineering actors such as architects, clients, owners, and contractors, suggests that detailed observational studies of the type we carried out are necessary to construct accurate portrayals of the role of each type of knowledge in various lines of work.

\section{Educational Implications}

The traditional approach to engineering education has been for students to learn theory in school and then learn the practice once on the job. Past research has argued against this model on the grounds that it inadequately prepares students for the range of knowledge demands of engineering work ${ }^{34} 3536$ and may systematically discourage promising recruits, including women and racial-minority students. ${ }^{37}$ Our finding that practice-generated knowledge dominates the work of structural engineers provides empirical justification for modifying the traditional university curriculum, reducing some of the emphasis on theory and other historically established information to make room for more practical learning. A modification of this type

\footnotetext{
${ }^{34}$ Jonassen, Strobel, and Lee, "Everyday Problem Solving in Engineering,” 2006.

${ }^{35}$ Evans, McNeill, and Beakley, "Design in Engineering Education,” 1990.

${ }^{36}$ Sheppard et al., Educating Engineers, 2008.

${ }^{37}$ Downey and Lucena, "Engineering Selves," 1997.
} 
would not only better mirror engineering work, it would also seem to ameliorate the problems that past research has identified.

Students could generate knowledge through practice in the course of their university education via a variety of means intended to simulate everyday, real-world engineering work. Lab courses, internships, and other field experiences, in which students can build a repertoire of knowledge about, and a feel for, structural materials and devices, are existing mechanisms whose use could be increased. Further, experiences with design and analysis software, as well as with physical materials and devices, would build students' knowledge of design instrumentalities and appropriate structural elements—-knowledge types that we observed the most frequently, but which tend to play more marginal roles in university training.

Problems assigned in engineering courses are another target for change. Bucciarelli noted that traditional textbook exercises expect students to strip away the trappings of the "real" situation to identify and work with the thinly disguised abstract mathematical or scientific principles underneath, while real engineering problems are inextricable from their physical contexts and do not embed clear-cut, ready-to-solve math problems. ${ }^{38}$ Indeed, engineers are often forced to generate knowledge in practice because there is no established method to solve the problem at hand. Conventional textbook exercises leave students with the impression that there will always be a standard method for solving engineering problems that will "work" (and finding that method is rarely problematic, since it has usually just been taught and can be found on the textbook pages immediately prior to the exercise). Exercises of this type are pedagogically

\footnotetext{
${ }^{38}$ Bucciarelli, Designing Engineers, 1994.
} 
useful when first learning a method, but our findings suggest that students should also experience problems that cannot be solved by routine application of an established method, namely, problems that require the use of rules of thumb and estimation as well as innovative uses or syntheses of established methods.

Replicating real-world conditions in university programs can be challenging, and this may be especially true in orchestrating authentic student experiences to build knowledge about engineering actors. Group design projects have long been used to develop skill in working with engineering colleagues, but a broader scope of knowledge would be addressed if design projects required negotiation with actual clients, architects, fabricators, tenants, or contractors. Involving these stakeholders, however, is often unfeasible or politically ill advised. An alternative would be for students to analyze case studies of actual projects and to propose design or negotiation solutions to problems arising from these cases. The payoff of incorporating learning about engineering actors in university programs could extend to recruitment. Characterizations of civil engineering currently presented to students almost certainly underplay the role of knowledge about people, which if more widely known might attract a different set of students.

Our findings also suggest that university curricula should reflect the changes in knowledge requirements across project phases. Although a single internship might not last long enough to expose a student to every phase, multiple field experiences could sample across phases. Case studies could also be strategically selected to represent different phases, perhaps in their chronological order. Instructors also could sequence course material to reflect the temporal patterns of a project's knowledge demands.

An important corollary of the preponderance of practice-generated knowledge is the idea that learning on the job is a central task of civil engineers. Not all practice-generated knowledge 
in this study was generated by the engineer observed to be using it, but much was, which suggests that generating knowledge and learning from experience are main components of this occupation. In prior work, Gainsburg documented veteran civil engineers making deliberate efforts to learn from practice, spending additional time on problems even after they had been "solved," in order to understand what the solution could teach them about future problems. ${ }^{39}$ Civil engineers, then, should not only to be trained to generate knowledge, but also encouraged to develop the disposition to learn from, employ, and generalize the knowledge generated at the individual and company level.

In general, changing the education of engineers to better reflect knowledge profiles of the disciplines should offer considerable advantages. Students would be better prepared to meet the demands of work upon hiring. They could make better-informed decisions when selecting a discipline of engineering and would have more realistic expectations for the work their chosen field entailed. And more accurate portrayals of engineering might attract a broader range of students to engineering, including students with talents or strengths for the more practical aspects of engineering work.

\footnotetext{
${ }^{39}$ Gainsburg, “Problem Solving and Learning in Everyday Structural Engineering Work,” 2007.
} 


\section{References}

Barley, Stephen R. "Technicians in the Workplace: Ethnographic Evidence for Bringing Work into Organization Studies.” Administrative Science Quarterly 41, no. 3 (1996): 404-441.

Barker, Roger G. ed. The Stream of Behavior: Explorations of Its Structure and Contents. New York: Appleton-Century-Crofts, 1963.

Bell, Daniel. The Coming of Post-Industrial Society: A Venture in Social Forecasting. New York: Basic Books, 1973.

Brown, John S. and Paul Duguid. “Organizational Learning and Communities-of-Practice: Toward a Unified View of Working, Learning, and Innovation.” Organization Science 2, no. 1 (1991): 40-57.

Bucciarelli, Louis L. Designing Engineers. Cambridge: MIT Press, 1994.

Cross, M.S. and Sivaloganathan, S. "Specialist Knowledge Identification, Classification, and Usage in Company-Specific New Product Development Processes.” Proceedings of the Institution of Mechanical Engineers, Part B: Journal of Engineering Manufacture 221, no. 8 (2007): 1285-1298.

Donovan, Arthur. “Thinking About Engineering.” Technology and Culture, 27, no. 4 (1986): 674-679.

Downey, Gary. L. and Juan C. Lucena. "Engineering Selves: Hiring Into a Contested Field of Education.” In Cyborgs and Citadels: Anthropological Interventions in Emerging Sciences and Technologies, edited by Gary L. Downey and Joseph Dumit, 117-142. Santa Fe: School of American Research Press, 1997.

Evans, Donovan L., Barry W. McNeill, and George C. Beakley. "Design in Engineering Education: Past Views of Future Directions.” Engineering Education, 80 (1990): 517522.

Faulkner, Wendy. "Conceptualizing Knowledge Used in Innovation: A Second Look at the Science-Technology Distinction and Industrial Innovation.” Science, Technology \& Human Values 19, no. 4 (1994): 425-458.

Gainsburg, Julie. "Problem Solving and Learning in Everyday Structural Engineering Work.” In Foundations for the Future in Mathematics Education, edited by Richard A. Lesh, Eric Hamilton, and James Kaput, 37-56. Mahwah, NJ: Lawrence Erlbaum Associates, 2007.

Henderson, Kathryn. On Line and On Paper: Visual Representations, Visual Culture, and Computer Graphics in Design Engineering. Cambridge: The MIT Press, 1999. 
Hutchins, Edwin. Cognition in the Wild. Cambridge: The MIT Press, 1995.

Jonassen, David, Johannes Strobel, and Chwee Beng Lee. "Everyday Problem Solving in Engineering: Lessons for Engineering Educators.” Journal of Engineering Education 95, no. 2 (2006): 139-151.

Lave, Jean. Cognition in Practice: Mind, Mathematics, and Culture in Everyday Life. Cambridge, England: Cambridge University Press, 1988.

Lave, Jean and Etienne Wenger. Situated Learning: Legitimate Peripheral Participation. Cambridge, England: Cambridge University Press, 1991.

Loch, Christoph H. and Christian Terwiesch. "Communication and Uncertainty in Concurrent Engineering.” Management Science 44, no. 8 (1998): 1032-1048.

Mer, Stéphane. "The Structural Engineer in the Design Office: A World, Its Objects, and Its Work Practices.” In Everyday Engineering: An Ethnography of Design and Innovation, edited by Dominique Vinck, 79-91. Cambridge, Massachusetts: MIT Press, 2003.

Orr, Julian E. Talking About Machines: An Ethnography of a Modern Job. Ithaca: ILP Press, 1996.

Polanyi, Michael. The Tacit Dimension. Garden City, New York: Doubleday, 1966.

Salvadori, Mario. Why Buildings Stand Up: The Strength of Architecture. New York: Norton, 1980.

Schön, Donald A. The Reflective Practitioner: How Professionals Think in Action. New York: Basic Books, 1983.

Sheppard, Sheri D., Kelly Macatangay, Anne Colby, and William M. Sullivan. Educating Engineers: Designing for the Future of the Field. San Francisco: Jossey-Bass, 2008.

Suchman, Lucy A. Plans and Situated Actions: The Problem of Human-Machine Communication. Cambridge, England: Cambridge University Press, 1987.

Vincenti, Walter G. What Engineers Know and How They Know It: Analytical Studies from Aeronautical History. Baltimore: Johns Hopkins University Press, 1990. 